\title{
The role of postoperative radiation and chemoradiation in Merkel cell carcinoma: a systematic review of the literature
}

\author{
Shaakir Hasan ${ }^{1}{ }^{*}$, Liyu Liu ${ }^{1}$, Jacob Triplet ${ }^{1}$, Zhen Li $^{2}$ and David Mansur ${ }^{3}$ \\ ${ }^{1}$ College of Osteopathic Medicine, Nova Southeastern University, Fort Lauderdale, FL, USA \\ ${ }^{2}$ Department of Neuroscience, Yale University, Hartford, CT, USA \\ ${ }^{3}$ Department of Radiation Oncology, University Hospitals at Case Western, Cleveland, OH, USA
}

Edited by:

Ajay Bhatnagar, University of

Pittsburgh School of Medicine, USA

\section{Reviewed by:}

Shisuo Du, New York University, USA Christopher Schultz, Medical College of Wisconsin, USA

*Correspondence: Shaakir Hasan, College of Osteopathic Medicine, Nova Southeastern University, 3301 College Avenue,

Fort Lauderdale, FL 33314, USA

e-mail:sh1055@nova.edu
Objective: A systematic review of the literature was undertaken to investigate whether adjuvant radiotherapy and/or chemotherapeutics offered any additional benefit than surgery alone in the treatment of Merkel Cell Carcinoma (MCC).

Methods: A PubMed, MEDLINE search was conducted between 1995 and 2013, to identify reported cases of surgically treated MCC followed by either observation, radiation, or chemoradiation. Patient demographics and outcomes were recorded and compared in a systematic fashion.

Results: Thirty-four studies ( $n=4475$ ) were included. The median age was 73 years, median follow up was 36 months and there was a 1.5:1 ratio of men to women. All 4475 patients had surgery, 1975 had no further treatment, 1689 received postoperative RT, and 301 received postoperative chemoRT. The most common site was face/head/neck, $47.8 \%$. Stage 1 was the most common clinical stage at diagnosis (57\%). Three-year local control was $20 \%$ (median 10\%) in the observation cohort, compared to 65\% (62\%) with postoperative RT, and $67 \%$ (75\%) with postoperative chemoRT; these findings were statistically significant $(P<0.001)$. Recurrence was found to be $38 \%(60 \%)$ in the observation cohort, compared to $23 \%(20 \%)$ with postoperative RT ( $P<0.001)$. Three-year overall survival (OS) was found to be $56 \%(57 \%)$ in the observation cohort, compared to $70 \%(78 \%)$ with postoperative RT and $73 \%(76 \%)$ with postoperative chemoRT $(P<0.001)$. The observation cohort had a median OS of 44 months compared with 64 months $(P<0.001)$ in the postoperative RT cohort. There was no statistically significant difference in any parameters assessed between postoperative radiation and postoperative chemoradiation arms.

Conclusion: The comprehensive collection of retrospective data suggests a survival and control benefit for postoperative radiation in MCC. No differences were noted between adjuvant radiation and chemoradiation. This analysis indicates the need for prospective trials with patients stratified by known prognostic factors.

Keywords: Merkel cell carcinoma, adjuvant radiotherapy, chemoradiation, postoperative radiation Merkel, review

\section{INTRODUCTION}

Merkel cell carcinoma (MCC) is an aggressive cutaneous malignancy that is known for its ability to metastasize, its high recurrence rate, and a mortality rate greater than that of melanoma. Merkel cells, first described in 1875 by Friedrich Merkel, are believed to be mechanoreceptors that relay information regarding light touch and hair movement $(1,2)$ Controversy exists as to the origin of these mechanoreceptors; both neural crest and epithelial origin have been suggested $(3,20)$ Regardless of its embryologic origin, its malignant transformation has devastating potential.

Merkel cell carcinoma is relatively rare, with an annual incidence rate of 0.6 per 100,000 (4). It affects nearly twice as many men as women and is more prevalent in whites than blacks, 94 and $1 \%$, respectively $(1,4,32)$. The average age of presentation for this malignancy is 72 years (1). The mean age of prevalence decreases dramatically, to 53 years of age, for immunocompromised individuals. Individuals with CLL, HIV/AIDS, and organ transplant recipients are at a 30,13 , and 10-fold increased risk respectively $(12,21,36)$.

Merkel cell is prevalent in sun-exposed areas, with nearly half of all incidences occurring in the head and neck region (29). In addition to sun-exposure, MCC has been associated with p53 mutations, arsenic exposure, Methoxsalen and ultraviolet-A treatment in psoriasis, and infrared skin damage $(1,12,13,29$, 48). Although these associations have been publicized, MCC has its strongest association with polyomavirus, present in $80 \%$ of cases (48).

The National Comprehensive Cancer Network (NCCN) 2013 guidelines recommend that patients with biopsy proven MCC undergo sentinel lymph node biopsy (SLNB) and appropriate 
immuno panel with wide local excision (WLE) of the primary tumor. The NCCN 2013 guidelines (http://www.nccn.org/ professionals/physician_gls/pdf/mcc.pdf) do not provide definitive recommendations for treatment of the various clinical stages of MCC. However, treatment options are still often based on the clinical stage of the cancer and consist of excision, radiation therapy, chemotherapy, or any combination of the three $(38,44)$. Traditionally, MCC is treated surgically, followed by radiation therapy in some instances although the radiosensitive nature of the tumor is not definitively established $(10,19,27)$. Radiation therapy alone may be used for patients who are not surgical candidates (38). The rationale for concomitant postoperative (chemoradiation) is that MCC is known to have chemosensitive based on, high initial response rates in metastatic settings $(9,16)$. Poulsen et al. (38) however demonstrated no significant difference in survival benefits with adjuvant chemotherapeutics compared with radiation therapy alone (40). Chemotherapy is typically reserved for patients with high risk of distant metastatic disease or those with existing metastatic disease.

Data supports the use of a $1-$ to $2-\mathrm{cm}$ margin for excision, although this remains controversial $(5,6,8,30)$. Alternative surgical options, such as the Moh's micrographic surgery, are also available. The Moh's technique has become increasingly popular due to its preservation of tissue, a cosmetic advantage, and has been shown to be comparable to that of WLE (7). Due to the lack of consensus for the treatment of MCC, a literature search was undertaken to investigate postoperative treatment modalities for MCC.

\section{MATERIALS AND METHODS STUDY SELECTION}

A PubMed, MEDLINE search was conducted between the years 1995-2013, to identify reported cases of surgically treated MCC. The following keyword combinations were used: MCC, surgery, postoperative management, combination treatment, radiation therapy, and chemoradiation therapy. The search was limited to studies published in English. A title and abstract review was then performed and reports from additional secondary references were also manually reviewed. Studies were included for their relevance to surgery only (observation), surgery combined with postoperative radiotherapy (RT) and/or surgery combined with postoperative chemoradiotherapy (chemoRT). Study types including retrospective, prospective and case series were reviewed. Commentaries, editorials, and review articles were excluded. WLE, defined as removal of the cancer accompanied by surrounding tissue, and Moh's micrographic surgery, defined as progressive removal of cancer-containing skin layers until only cancer-free tissue remains, were the majority of the surgical techniques included in this review. In cases where radiotherapy was used, radiation was localized and the dose was between 45 and $65 \mathrm{~Gy}$ (median of $50 \mathrm{~Gy}$ ), with 3-4 cm margins. Chemotherapeutics used in the literature include carboplatin, etoposide, cyclophosphamide, doxorubicin, epirubicin, vincristine, cisplatin, capecitabine, or any combination.

\section{DATA EXTRACTION}

Patient characteristics including age, gender, size and location of primary tumor, clinical stage, and nodal involvement were reported. The following system was used to standardize clinical stages: stage I indicated localized primary tumor of any size, without evidence of lymph node involvement or distant metastasis; Stage II indicated regional lymph node involvement (regional draining lymph nodes or adjacent lymph nodes) without distant metastasis; Stage III was evidence of distant disease. Primary treatment were carefully reviewed and categorized into three modalities: observation, RT, and chemoRT. Assessment of outcomes were reviewed and reported as overall survival (OS), OS after 1 year, after 3 years, local control (LC) after 1 year, 3 years, crude recurrence (including local recurrence and/or nodal/distant relapse), time to recurrence, and toxicity.

\section{INCLUSION CRITERIA}

The following inclusion criteria were applied to each study:

- Primary tumor of MCC in any stage

- Positive or negative metastases to lymph nodes

- Lesions of any size

- Primary treatment included curative surgery (Moh's micrographic surgery or WLE) followed by observation, surgery followed by radiation within 3 months, or surgery followed by concurrent chemoradiation within 3 months.

\section{EXCLUSION CRITERIA}

- Unknown primary tumor

- Treatment of recurrent MCC

- Primary treatment did not include surgery

- Radiation or chemoradiotherapy used as salvage therapy

- Insufficient documentation.

\section{STATISTICAL ANALYSIS}

Treatment modalities were correlated to different outcome. $T$ tests, odds ratios, and chi square testing was used when appropriate using the software SOFA and MedCalc.

\section{RESULTS}

\section{STUDY SELECTION}

An initial search yielded 271 records from PubMed. An additional 12 secondary references were also reviewed (Figure 1). Abstract review and manual review from an additional 12 secondary references were performed and 34 studies (a total patient number of $n=4475$ ) were included for their fulfillment of inclusion criteria listed above and relevance to the three treatment modalities of interest (Figure 1). Out of the 34 studies, there were 31 retrospective studies (a total patient number of $n=4315$ ); 2 studies reported surgery combined with chemoradiotherapy $(n=46)$, seven studies reported treatment modalities of surgery alone vs. surgery combined with post-op radiotherapy $(n=2220)$, and 22 studies reported all three treatment modalities of interests $(n=2049)$. Out of the 34 studies, there were three prospective studies; two studies evaluated post-op chemoradiotherapy only $(n=58)$ while one study evaluated all three treatment modalities of interest $(n=102)$. Not all cases of MCC treated by surgery could be included in every parameter assessed.

\section{DEMOGRAPHICS}

The median age of patients included in analysis was 73 years (6380 ) for all three treatment arms and there was a 1.5:1 ratio of men 


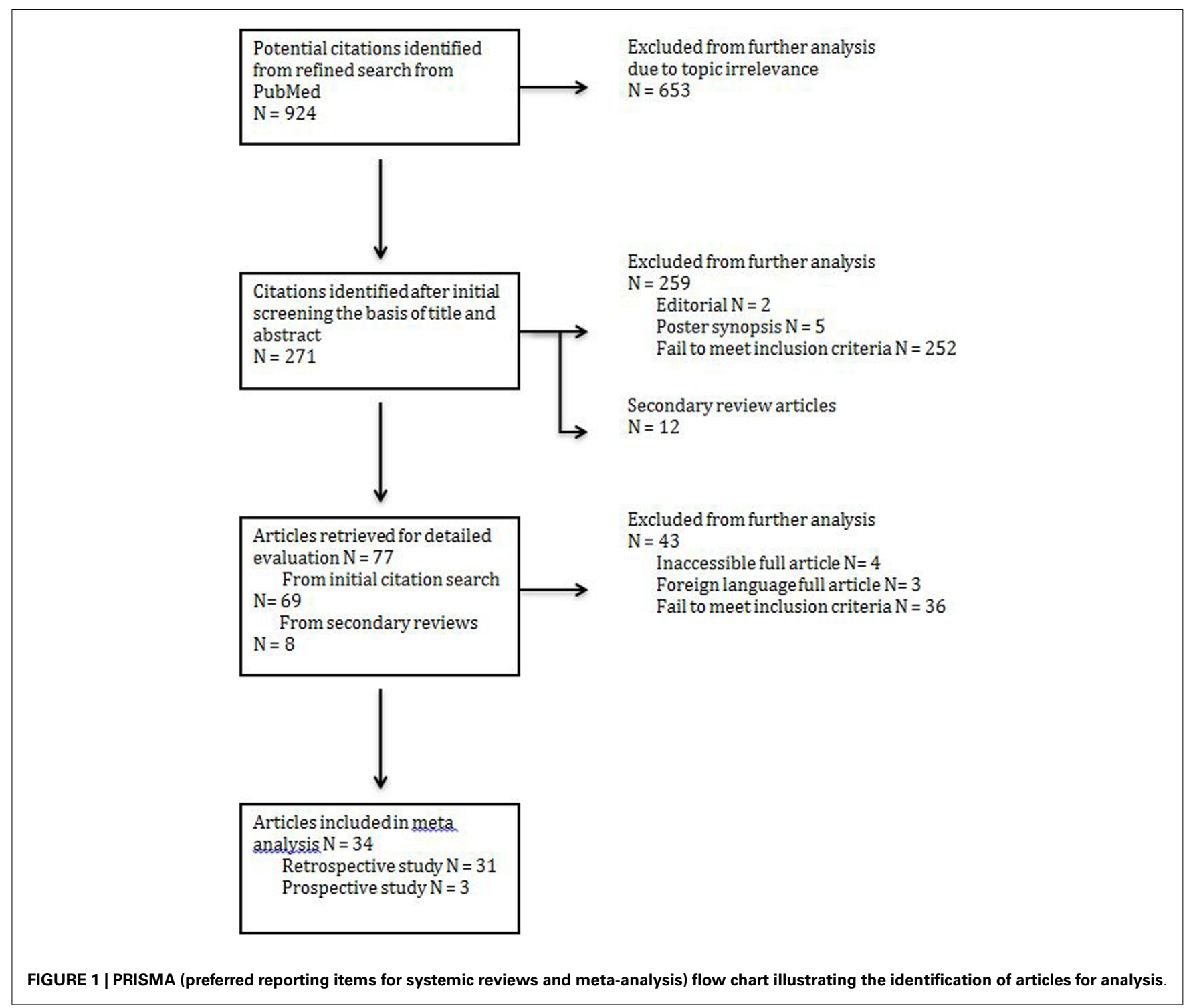

to women. The median follow up period was 36 months (range 7-60). All 4475 patients included in the review had surgery, 1975 patients had no further treatment (observation), 1689 received postoperative radiotherapy (RT), and 301 received postoperative chemoradiotherapy (chemoRT). The most common primary site was the face/head/neck, representing $47.8 \%(n=1327)$ of all cases (Table 1). The most common clinical stage at diagnosis was Stage I local disease, which represented 57\% $(n=2037)$ of all cases, although this was not equally represented in each cohort. Stage 1 disease represented $67 \%$ and $60 \%$ of all cases that received observation and radiation therapy post-surgery, respectively, but represented $29 \%$ of all cases that received postoperative chemoradiotherapy. Stage 2 , which indicates clinical involvement of regional lymph nodes represented 30\% overall, 39\% of RT cohort and $57 \%$ of postoperative chemoRT cohort. Report of nodal status (clinical and histological) and treatment of regional nodes (positive or negative) included regional or radical dissection, biopsy, and irradiation. Most nodal treatments were dependent on clinician preference and was inconsistent across studies.

\section{LOCAL CONTROL AND CRUDE RECURRENCE}

Local control was defined as the percentage of patients with no evidence of disease at the primary site or regional lymph nodes at follow up. The weighted mean for 3-year LC rate was $20 \%$ in the observation cohort with a median of $10 \%$. This is compared to a median of $66 \%$ of patients achieving LC $(P<0.001)$ after receiving postoperative radiation therapy. Three-year LC rate was $67 \%$ with postoperative chemoradiation with a median of $75 \%$ in comparison to $20 \%$ in the observation cohort $(P<0.001)$. Crude recurrence was defined as any documented recurrence of neoplasm including local, nodal, or distant metastatic recurrences anytime during the follow up period. In the observation group, there was a $38 \%$ recurrence rate (with a median of $60 \%$ ) compared to a $23 \%$ recurrence 
Table 1 | Summary of patient demographics.

\begin{tabular}{|c|c|c|c|c|c|c|c|}
\hline \multirow{2}{*}{$\begin{array}{l}\text { Characteristics } \\
\text { Patient }\end{array}$} & \multirow{2}{*}{$\begin{array}{c}\text { Total/weighted mean } \\
4775\end{array}$} & \multicolumn{2}{|c|}{ Observation } & \multicolumn{2}{|c|}{ Surgery + RT } & \multicolumn{2}{|c|}{ Surgery + ChemoRT } \\
\hline & & 1975 & $\%$ & 1689 & $\%$ & 301 & $\%$ \\
\hline \multicolumn{8}{|l|}{ Gender } \\
\hline Female & 1679 & 451 & 43 & 360 & 41 & 44 & 27 \\
\hline \multicolumn{8}{|l|}{ Age } \\
\hline Median (months) & 35.8 & 50.2 & & 47.4 & & 25.8 & \\
\hline \multicolumn{8}{|l|}{ Clinical stage } \\
\hline I & 2094 & 720 & 67 & 650 & 60 & 36 & 36 \\
\hline II & 1006 & 347 & 33 & 423 & 39 & 55 & 54 \\
\hline III & 276 & 3 & 0.2 & 2 & 0.2 & 10 & 10 \\
\hline Extremities & 993 & 148 & 45 & 161 & 41 & 58 & 36 \\
\hline Face/head/neck & 1327 & 151 & 46 & 177 & 45 & 66 & 41 \\
\hline Trunk & 262 & 31 & 9 & 54 & 14 & 8 & 5 \\
\hline Other & 197 & 0 & 0 & 0 & 0 & 28 & 18 \\
\hline
\end{tabular}

Observation, surgery only treatment group; RT, received postoperative radiation therapy; ChemoRT, received postoperative chemoradiation therapy.

Table 2 | Outcome summary of retrospective studies.

\begin{tabular}{|c|c|c|c|c|c|c|}
\hline & Observation & Median & Surgery + RT & Median & Surgery + ChemoRT & Median \\
\hline & 44 & & 64 & & $84^{a}$ & \\
\hline 1 year Overall survival (\%) & 81 & 89 & 90 & 90 & 89 & 100 \\
\hline Crude recurrence (\%) & 38 & 60 & 23 & 20 & 22 & 35 \\
\hline Time to recurrence (months) & 9 & & 16 & & 170 & \\
\hline
\end{tabular}

Observation, surgery only treatment group; $R T$, received postoperative radiation therapy; ChemoRT, received postoperative chemoradiation therapy.

a Only one point of reference.

in of the postoperative radiotherapy group (median of 20\%) $(P<0.001)$ (Table 2$)$. There was no statistically significant difference in any control or recurrence parameters assessed between postoperative radiation and postoperative chemoradiation arms (Table 3).

\section{SURVIVAL}

The 1-year OS was $81 \%$ with the median of $89 \%$ in the observation cohort in comparison to $90 \%$ and a median of $90 \%$ the postoperative radiation cohort $(P<0.001)$. The 1 -year OS in the postoperative chemoradiation therapy cohort was $89 \%$ $(P<0.001)$ in comparison to observation with a median of $100 \%$. The 3-year OS was $55 \%$ in observation (median of $57 \%$ ) in comparison to $70 \%$ (median of $78 \%$ ) in the postoperative radiation cohort $(P<0.001)$, and $73 \%$ (median of $76 \%)$ in postoperative chemoradiation cohort when compared to observation $(P<0.001)$. The median OS in months was 44 months in the
Table 3 | Outcome summary of prospective studies.

\begin{tabular}{lccc}
\hline & Observation & Surgery + RT & Surgery + ChemoRT (\%) \\
\hline Acute toxicity & - & - & 45 \\
Chronic toxicity & - & - & $17^{\mathrm{a}}$ \\
Crude recurrence & - & $42 \%^{\mathrm{a}}$ & 31
\end{tabular}

Observation, surgery only treatment group; $R T$, received postoperative radiation therapy; ChemoRT, received postoperative chemoradiation therapy.

${ }^{a}$ Only one point of reference.

observation cohort in comparison to 64 months in the postoperative radiation cohort $(P<0.001)$. Again there were no statistically significant differences in any survival parameters assessed between postoperative radiation and postoperative chemoradiation arms (Table 3). 


\section{SUBSET ANALYSIS}

A subset analysis was performed contrasting observation and RT treatments based on the size of the tumor; chemoRT was excluded due to lack of data. Collected data was separated into two groups (either $<2 \mathrm{~cm}$ or $\geqq 2 \mathrm{~cm}$ ) based on the mean tumor size for the study; it does not indicate that all tumors in the study were $<2 \mathrm{~cm}$ or $\geqq 2 \mathrm{~cm}$. Only studies where mean tumor size could be attained were included in this subset analysis.

Group $1(<2 \mathrm{~cm})$ median overall survival for postoperative observation group and RT group was 45.7 months and 53.9 months $(P<0.001)$ respectively; Group $2(\geqq 2 \mathrm{~cm})$ OS was 45 months and 63 months $(P<0.001)$ respectively (Figure 2$)$. For tumors $<2 \mathrm{~cm}$, the 3 -year OS was $55.4 \%$ and $74.6 \%(P<0.001)$ for observation and postoperative radiation respectively. Similar trends were also noted for tumors $>2 \mathrm{~cm}$ for 3-year OS $(56.4 \%$ with observation vs. 69.8\% with radiation) (Figure 3). The $<2 \mathrm{~cm}$ 1 -year local control rate (LC) was $52.9 \%$ and $89.2 \%(P<0.001)$ for observation and radiation, respectively; and the difference was even more pronounced for the tumors $>2 \mathrm{~cm}$ (38\% vs. $83 \%)$. Similarly, the 3 -year LC for tumors $<2 \mathrm{~cm}$ was $31.6 \%$ and $75.9 \%$ $(P<0.001)$ for observation and radiation, respectively; compared to $8 \%$ with observation and $64.7 \%$ with radiotherapy $(P<0.001)$ for tumors $>2 \mathrm{~cm}$ (Figure 3 ).

\section{DISCUSSION}

The diagnosis of MCC, made difficult by its lack of clinical symptoms, has devastating potential. Immunostains have contributed greatly to earlier diagnosis of this rare cancer. Despite the modern advances in diagnostic abilities, there is little uniformity of the treatment protocol for MCC. Surgical excision of the primary tumor is most commonly practiced with little dispute. However, few guidelines exist to direct treatment based on variables such as clinical stage and size of the primary tumor. To our knowledge, no definitive recommendations exist for the adjuvant treatment of radiotherapy and/or chemotherapeutics. MCC is known to be a radiosensitive cancer, though adjuvant radiotherapy is at the discretion of the treating physician. Chemotherapeutics have been proven to have an initial response in metastatic setting (2), but its use in the treatment of localized MCC is controversial.

This systematic review supports the use of adjuvant treatment with surgical excision based on the retrospective data (Table 4). The data suggests a benefit of postoperative radiation for MCC in terms of OS. Adjuvant radiotherapy 3-year OS was 14.2\% greater for the radiotherapy arm $(70.4 \%)$ than the observation group $(56.2 \%)$. Upon subset analysis, studies with an average tumor $<2 \mathrm{~cm}$ demonstrated a 3 -year OS that was $19.2 \%$ greater for the radiotherapy arm $(74.6 \%)$ than the observation group (55.4\%). Studies with tumors $\geqq 2 \mathrm{~cm}$ demonstrated a 3 -year OS that was $13.4 \%$ greater for the radiotherapy arm $(69.8 \%)$ than the observation group (56.4\%).

Adjuvant radiotherapy and chemoradiotherapy were both shown to be advantageous in LC compared with surgical excision alone. Three-year LC was $45.1 \%$ greater for the radiotherapy $\operatorname{arm}(64.6 \%)$ than the observation group (19.5\%). Subset analysis demonstrated a $44.3 \%$ difference in 3-year LC for tumors $<2 \mathrm{~cm}$ for the radiotherapy arm $(75.9 \%)$ than the observation group (31.6\%), and a $56.7 \%$ difference in 3 -year LC for tumors $\geqq 2 \mathrm{~cm}$
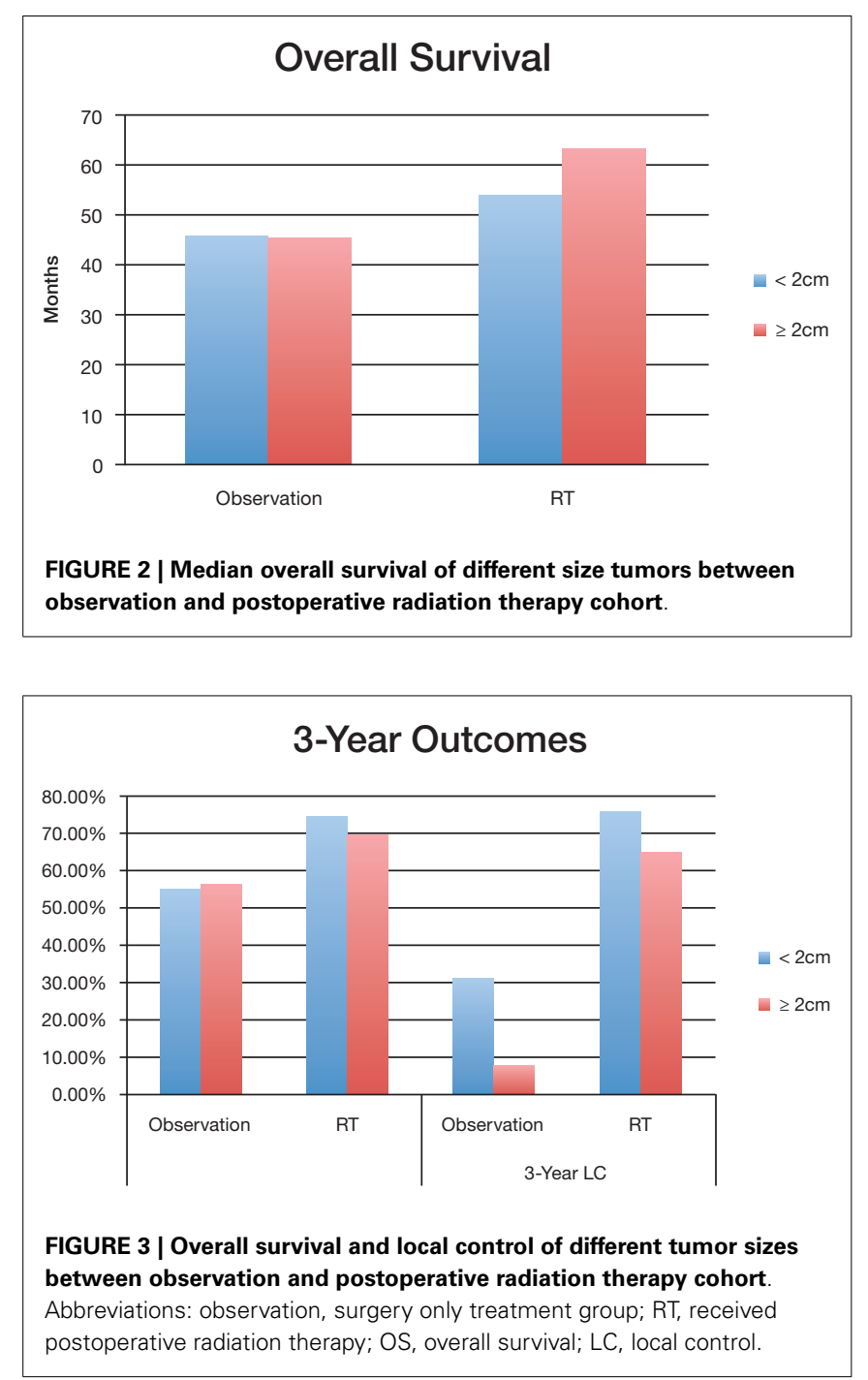

for the radiotherapy arm $(64.7 \%)$ than the observation group $(8 \%)$. These outcomes existed despite the fact that there were more patients with later stage disease in the radiation cohort. Chemoradiotherapy did not demonstrate any added benefits compared with radiotherapy alone in regards to LC.

Based on the pattern that current studies reveal, we recommend that a large prospective trial should be conducted to evaluate the true effect of postoperative radiation. Adjuvant radiotherapy was statistically significant for improvement of both OS and local recurrence. There was no statistically significant difference in any control or recurrence parameters assessed between postoperative RT and postoperative chemoRT arms. Adjuvant chemoRT did not significantly improve OS compared with radiotherapy alone. However, analysis of the primary tumor characteristics revealed that tumor stages and regional lymph node involvement were not equally represented among the three treatment cohorts. In particular, $56 \%$ of the patients receiving chemotherapy had stage II tumor and $10 \%$ of the patients had stage III tumor; both are significantly more common than patients receiving postoperative radiation therapy (39 and $0.5 \%$, respectively). Also, $65 \%$ of the 
Table 4 | Summary of age, follow up, size, nodal status, and outcome across three treatment cohort from 34 original studies.

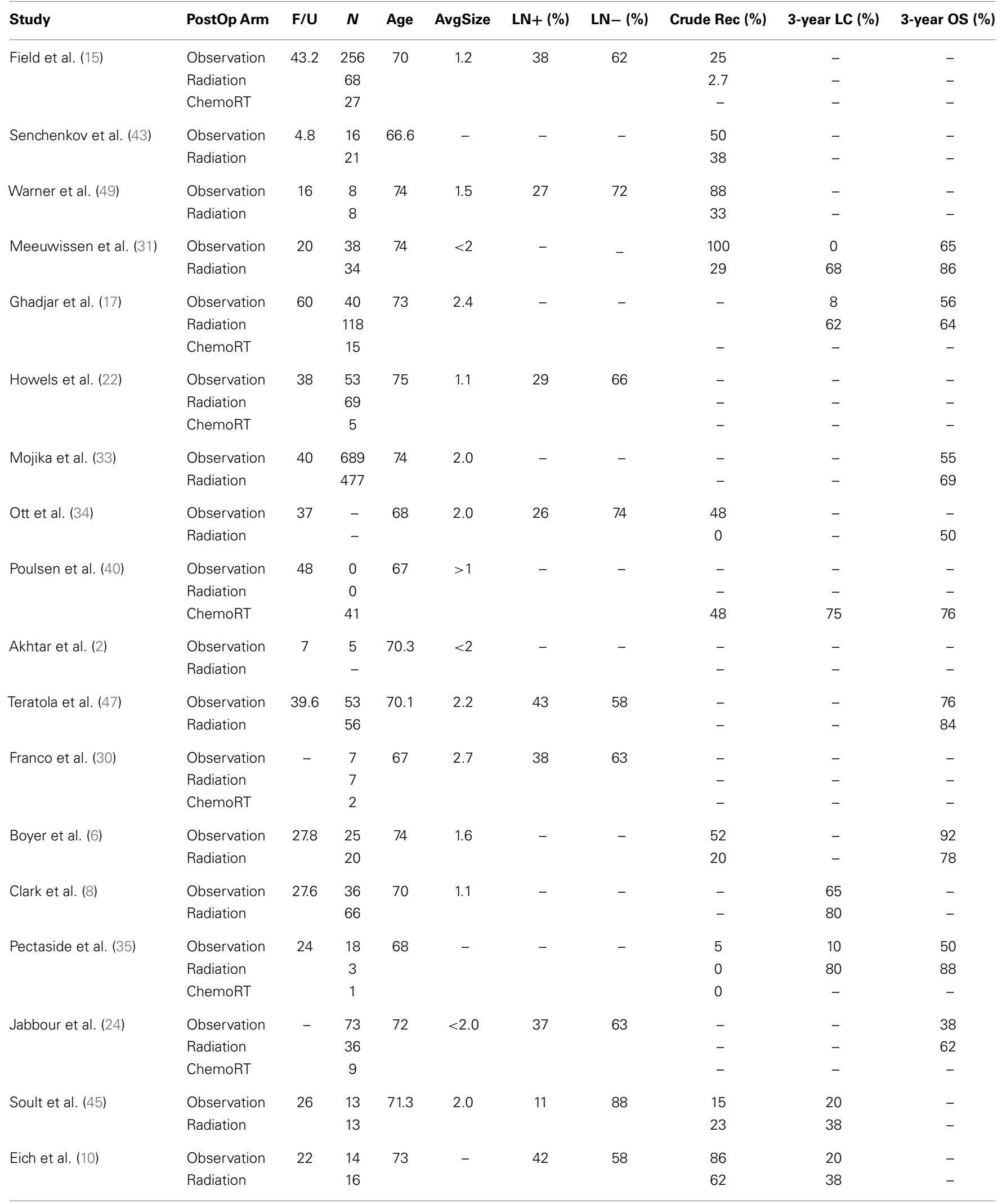


Table 4 | Continued

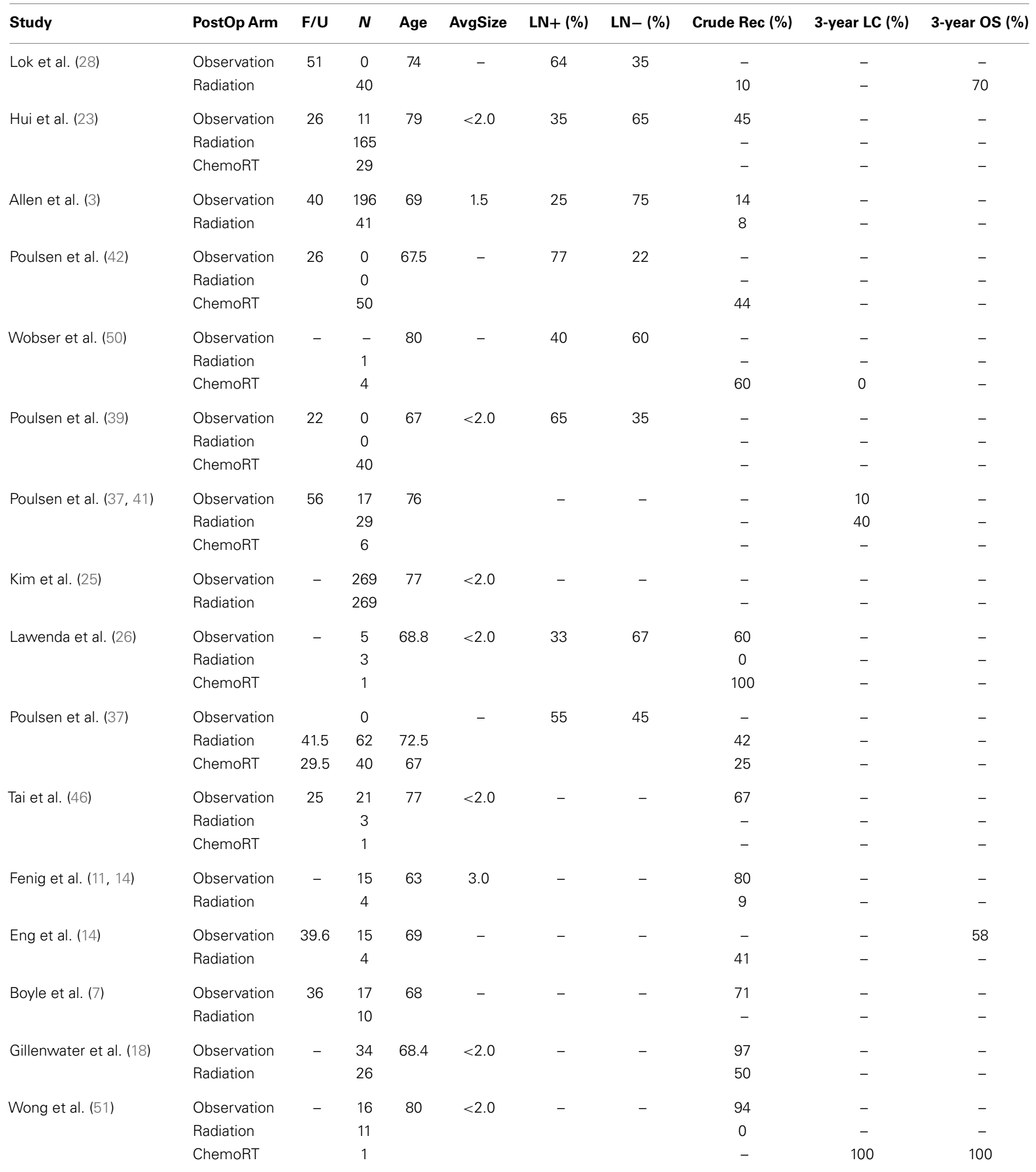

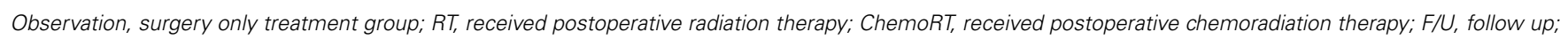
$L N$, regional lymph node involvement; OS, overall survival; $L C$, local control. 
chemoRT patients were positive for clinical nodal involvement, compared to $35 \%$ in the overall cohort. In this review, chemoRT group had significantly fewer points of reference $(n=301)$ than the RT group $(n=1689)$. Chemotherapeutics may play a role in more advanced MCC, though limited data makes their role unproven. ChemoRT should also be considered in patients who are unresponsive to radiotherapy alone. Addition of chemotherapeutics should be used cautiously due to its toxicity. ChemoRT was shown to have statistically significant increase in both acute $(P=0.002)$ and chronic $(P<0.001)$ toxicity when compared with radiotherapy alone.

Merkel cell carcinoma is a cancer that has great metastasis potential. Though some physicians use size as a factor in determining the use of adjuvant treatments, no definitive guidelines have been published. In this review, we compared the mean primary tumor size among various publications. We separated all studies into one of two groups; Group 1 had a mean tumor size $<2 \mathrm{~cm}$ and Group 2 had a mean tumor size $\geqq 2 \mathrm{~cm}$. This division has a major limitation; the groups are based on the mean of the study, not the mode. This division may skew the size of the majority of that study secondary to a few extremely large tumors. Though this classification system is not ideal, the results of this review support the use of radiotherapy regardless of tumor size. Mojika and colleagues (33) analyzed retrospective data from 1665 patient from the National Cancer Institute; this data suggested that overall median survival in months of patients were improved through the use of adjuvant radiation therapy in comparison to surgery alone, despite the size of the primary tumor. They further suggest that survival improvement was most prominent when primary tumors are larger than $2 \mathrm{~cm}$.

Future research endeavors warrant comparison of radiotherapy and chemoradiotherapy adjuvants for advance stage MCC. This comparison will directly show if there is any added benefit to chemotherapeutics. Furthermore, it will also establish data from which recommendations for adjuvant treatments may be established based on clinical staging. Current study did not yield enough well documented cases to compare the two cohort directly. While this comprehensive retrospective analysis in a broad patient population reflects an advantage for postoperative radiation, there could be certain prognostic factors in a given patient that may favor surgery alone. Many variables may play a role in the success of treatment for MCC. Primary tumor size, nodal involvement and presence of metastasis should be recorded for points of data for future research. These variables may play a critical role in the establishment of treatment guidelines for MCC as well.

This review has several limitations; mostly a product of the retrospective nature of the studies included which is insufficient basis to recommend standard of care. Poulsen conducted the only three prospective studies conducted on postoperative management of MCC, and they all addressed adjuvant chemoradiation against adjuvant radiation alone $(37,39,42)$. No randomized trial has ever been conducted regarding the role of radiation in MCC and the current clinical trials all address the use of certain immunotherapies that have been successful in other skin cancers. Although we attempted to make cohorts similar through certain subset analyses, a true comparison of outcomes of patients with the same stage, tumor size, or nodal involvement could not be accomplished due to a lack of original patient data. The trend identified by current study support the use of postoperative radiation for MCC. The data on postoperative chemoradiation, on the other hand, was restricted enough by the studies limitations so that no trend could be discovered.

\section{CONCLUSION}

This systematic review demonstrates that the use of adjuvant radiotherapy in the treatment of MCC, regardless of tumor size, location, or nodal involvement, resulted in survival and control benefit reported in the literature. However, standard documentation of retrospective data and large scale prospective studies are needed to consolidate current trend. The use of adjuvant chemoradiotherapy remains unproven, although there may be a benefit in systemic disease. Establishment of treatment guidelines is needed.

\section{REFERENCES}

1. Agelli M, Clegg LX. Epidemiology of primary Merkel cell carcinoma in the United States. J Am Acad Dermatol (2003) 49:832-41. doi:10.1016/S01909622(03)02108-X

2. Akhtar S, Oza KK, Wright J. Merkel cell carcinoma: report of 10 cases and review of the literature. J Am Acad Dermatol (2000) 43:755-67. doi:10.1067/mjd.2000. 106505

3. Allen PJ, Bowne WB, Jaques DP, Brennan MF, Busam K, Coit DG. Merkel cell carcinoma: prognosis and treatment of patients from a single institution. J Clin Oncol (2005) 23:2300-9. doi:10.1200/JCO.2005.02.329

4. Baumann KI, Halata Z, Moll I, editors. The Merkel Cell: Structure-DevelopmentFunction-Cancerogenesis. Berlin: Springer (2003). p 1-248.

5. Bichakjian CK, Lowe L, Lao CD, Sandler HM, Bradford CR, Johnson TM, et al. Merkel cell carcinoma: critical review with guidelines for multidisciplinary management. Cancer (2007) 110:1-12. doi:10.1002/cncr.22765

6. Boyer JD, Zitelli JA, Brodland DG, D’Angelo G. Local control of primary Merkel cell carcinoma: review of 45 cases treated with Mohs micrographic surgery with and without adjuvant radiation. J Am Acad Dermatol (2002) 47:885-92. doi:10.1067/mjd.2002.125083

7. Boyle F, Pendlebury S, Bell D. Further insights into the natural history and management of primary cutaneous neuroendocrine (Merkel cell) carcinoma. Int J Radiat Oncol Biol Phys (1995) 31:315-23. doi:10.1016/0360-3016(93)E0110-R

8. Clark JR, Veness MJ, Gilbert R, O’Brien CJ, Gullane PJ. Merkel cell carcinoma of the head and neck: is adjuvant radiotherapy necessary? Head Neck (2007) 29:249-57. doi:10.1002/hed.20510

9. Desch L, Kunstfeld R. Merkel cell carcinoma: chemotherapy and emerging new therapeutic options. J Skin Cancer (2013) 2013:327150. doi:10.1155/2013/ 327150

10. Eich HT, Eich D, Staar S, Mauch C, Stutzer H, Groth W, et al. Role of postoperative radiotherapy in the management of Merkel cell carcinoma. Am J Clin Oncol (2002) 25:50-6.

11. Eng TY, Boersma MG, Fuller CD, Cavanaugh SX, Valenzuela F, Herman TS. Treatment of Merkel cell carcinoma. Am J Clin Oncol (2004) 27:510-5. doi:10.1590/S1807-59322011001000023

12. Engels EA, Frisch M, Goedert JJ, Biggar RJ, Miller RW. Merkel cell carcinoma and HIV infection. Lancet (2002) 359:497-8. doi:10.1016/S0140-6736(02)07668-7

13. Feng H, Shuda M, Chang Y, Moore PS. Clonal integration of a polyomarvirus in human Merkel cell carcinoma. Science (2008) 319:1096-100. doi:10.1126/ science. 1152586

14. Fenig E, Brenner B, Katz A, Rakovsky E, Hana MB, Sulkes A. The role of radiation therapy and chemotherapy in the treatment of Merkel cell carcinoma. Cancer (1997) 80:881-5.

15. Fields RC, Busam KJ, Chou JF, Panageas KS, Pulitzer MP, Allen PJ, et al. Recurrence after complete resection and selective use of adjuvant therapy for stage I through III Merkel cell carcinoma. Cancer (2012) 118:3311-20. doi:10.1002/cncr.26626

16. Shalhub S, Clarke L, Morgan MB. Chemotherapy for metastatic Merkel cell carcinoma. Cancer (1985) 56:1034-8. 
17. Ghadjar P, Kaanders JH, Poortmans P, Zaucha R, Krengli M, Lagrange JL, et al. The essential role of radiotherapy in the treatment of Merkel cell carcinoma: a study from the rare cancer network. Int J Radiat Oncol Biol Phys (2011) 81:e583-91. doi:10.1016/j.ijrobp.2011.05.028

18. Gillenwater AM, Hessel AC, Morrison WH, Burgess M, Silva EG, Roberts D, et al. Merkel cell carcinoma of the head and neck: effect of surgical excision and radiation on recurrence and survival. Arch Otolaryngol Head Neck Surg (2001) 127:149-54. doi:10.1001/archotol.127.2.149

19. Goessling W, McKee PH, Mayer RJ. Merkel cell carcinoma. J Clin Oncol (2002) 20:588-98. doi:10.1200/JCO.20.2.588

20. Halata Z, Baumann KI. Friedrich Sigmund Merkel and his "Merkel cell," morphology, development, and physiology: review and new results. Anat Rec A Discov Mol Cell Evol Biol (2003) 271:225-39. doi:10.1002/ar.a.10029

21. Heath M, Jaimes N, Lemos B, Mostaghimi A, Wang LC, Peñas PF, et al. Clinical characteristics of Merkel cell carcinoma at diagnosis in 195 patients: the Aeiou features. J Am Acad Dermatol (2008) 58:375-81. doi:10.1016/j.jaad.2007.11.020

22. Howle JR, Hughes TM, Gebski V, Veness MJ. Merkel cell carcinoma: an Australian perspective and the importance of addressing the regional lymph nodes in clinically node-negative patients. J Am Acad Dermatol (2012) 67:33-40. doi:10.1016/j.jaad.2011.07.029

23. Hui AC, Stillie AL, Seel M, Ainslie J. Merkel cell carcinoma: 27-year experience at the Peter Maccallum cancer centre. Int J Radiat Oncol Biol Phys (2011) 80:1430-5. doi:10.1016/j.ijrobp.2010.04.061

24. Jabbour J, Cumming R, Scolyer RA, Hruby G, Thompson JF, Lee S. Merkel cell carcinoma: assessing the effect of wide local excision, lymph node dissection, and radiotherapy on recurrence and survival in early-stage disease - results from a review of 82 consecutive cases diagnosed between 1992 and 2004. Ann Surg Oncol (2007) 14:1943-52. doi:10.1245/s10434-006-9327-y

25. Kim JA, Choi AH. Effect of radiation therapy on survival in patients with resected Merkel cell carcinoma: a propensity score surveillance, epidemiology, and end results database analysis. JAMA Dermatol (2013) 149:831-8. doi:10.1001/jamadermatol.2013.409

26. Lawenda BD, Thiringer JK, Foss RD, Johnston PAS. Merkel cell carcinoma arising in the head and neck. Am J Clin Oncol (2001) 24:35-42.

27. Lee J, Poon I, Balogh J, Tsao M, Barnes E. A review of radiotherapy for Merkel cell carcinoma of the head and neck. J Skin Cancer (2012) 2012:563829. doi:10.1155/2012/563829

28. Lok B, Khan S, Mutter R, Liu J, Fields R, Pulitzer M, et al. Selective radiotherapy for the treatment of head and neck Merkel cell carcinoma. Cancer (2012) 118:3937-44. doi:10.1002/cncr.26738

29. Lunder EJ, Stern RS. Merkel cell carcinomas in patients treated with methoxsalen and ultraviolet a radiation. N Engl J Med (1998) 339:1247-8.

30. Medina-Franco H, Urist MM, Fiveash J, Heslin MJ, Bland KI, Beenken SW. Multimodality treatment of Merkel cell carcinoma: case series and literature review of 1024 cases. Ann Surg Oncol (2001) 8:204-8.

31. Meeuwissen JA, Bourne RG, Kearsley JH. The importance of postoperative radiation therapy in the treatment of Merkel cell carcinoma. Int J Radiat Oncol Biol Phys (1995) 31:325-31.

32. Miller RW, Rabkin CS. Merkel cell carcinoma and melanoma: etiological similarities and differences. Cancer Epidemiol Biomarkers Prev (1999) 8:153-8.

33. Mojica P, Smith D, Ellenhorn JD. Adjuvant radiation therapy is associated with improved survival in Merkel cell carcinoma of the skin. J Clin Oncol (2007) 25:1043-7. doi:10.1200/JCO.2006.07.9319

34. Ott MJ, Tanabe KK, Gadd MA, Stark P, Smith BL, Finkelstein DM, et al. Multimodality management of Merkel cell carcinoma. Arch Surg (1999) 134:388-93.

35. Pectasides D, Papaxoinis G, Pectasides E, Galani H, Razi E, Katodrytis N, et al. Merkel cell carcinoma of the skin: a retrospective study of 24 cases by the Hellenic Cooperative Oncology Group. Oncology (2007) 72:211-8. doi: $10.1159 / 000112944$

36. Penn I, First MR. Merkel's cell carcinoma in organ recipients: report of 41 cases. Transplantation (1999) 68:1717-21.

37. Poulsen MG, Rischin D, Porter I, Walpole E, Harvey J, Hamilton C, et al. Does chemotherapy improve survival in high-risk stage I and II Merkel cell carcinoma of the skin? Int J Radiat Oncol Biol Phys (2006) 64:114-9. doi:10.1016/j.ijrobp.2005.04.042
38. Poulsen M, Rischin D. Merkel cell carcinoma - current therapeutic options. Expert Opin Pharmacother (2003) 4:2187-92. doi:10.1517/14656566.4.12.2187

39. Poulsen M, Rischin D, Walpole E, Harvey J, Macintosh J, Ainslie J, et al. Analysis of toxicity of Merkel Cell carcinoma of the skin treated with synchronous carboplatin/etoposide and radiation: a Trans-Tasman Radiation Oncology Group Study. Int J Radiat Oncol Biol Phys (2001) 51:156-63. doi:10.1016/S03603016(01)01577-2

40. Poulsen M, Rischin D, Walpole E, Harvey J, Mackintosh J, Ainslie J, et al. High-risk Merkel cell carcinoma of the skin treated with synchronous carboplatin/etoposide and radiation: a Trans-Tasman Radiation Oncology Group Study - Trog 96:07. J Clin Oncol (2003) 21:4371-6. doi:10.1200/JCO. 2003.03.154

41. Poulsen M, Round C, Keller J, Tripcony L, Veness M. Factors influencing relapsefree survival in Merkel cell carcinoma of the lower limb - a review of 60 cases. Int J Radiat Oncol Biol Phys (2010) 76:393-7. doi:10.1016/j.ijrobp.2009.02.014

42. Poulsen M, Walpole E, Harvey J, Dickie G, O’Brien P, Keller J, et al. Weekly carboplatin reduces toxicity during synchronous chemoradiotherapy for Merkel cell carcinoma of skin. Int J Radiat Oncol Biol Phys (2008) 72:1070-4. doi:10. 1016/j.ijrobp.2008.02.076

43. Senchenkov A, Barnes SA, Moran SL. Predictors of survival and recurrence in the surgical treatment of Merkel cell carcinoma of the extremities. J Surg Oncol (2007) 95:229-34. doi:10.1002/jso.20647

44. Senchenkov A, Moran SL. Merkel cell carcinoma: diagnosis, management, and outcomes. Plast Reconstr Surg (2013) 131:771-8. doi:10.1097/PRS. 0b013e3182865cf3

45. Soult MC, Feliberti EC, Silverberg ML, Perry RR. Merkel cell carcinoma: high recurrence rate despite aggressive treatment. J Surg Res (2012) 177:75-80. doi:10.1016/j.jss.2012.03.067

46. Tai PTH, Yu E, Winquist E, Hammond A, Stitt L, Tonita J, et al. Chemotherapy in neuroendocrine/Merkel cell carcinoma of the skin: case series and review of 204 cases. J Clin Oncol (2000) 18:2493-9.

47. Tarantola TI, Vallow LA, Halyard MY, Weenig RH, Warschaw KE, Grotz TE, et al. Prognostic factors in Merkel Cell carcinoma: analysis of 240 cases. J Am Acad Dermatol (2013) 68:425-32. doi:10.1016/j.jaad.2012.09.036

48. Van Gele M, Kaghad M, Leonard JH, Van Roy N, Naeyaert JM, Geerts ML, et al. Mutation analysis of P73 and Tp53 in Merkel cell carcinoma. Br J Cancer (2000) 82:823-6. doi:10.1054/bjoc.1999.1006

49. Warner RE, Quinn MJ, Hruby G, Scolyer RA, Uren RF, Thompson JF. Management of Merkel cell carcinoma: the roles of lymphoscintigraphy, sentinel lymph node biopsy and adjuvant radiotherapy. Ann Surg Oncol (2008) 15:2509-18. doi:10.1245/s10434-008-9983-1

50. Wobser M, Kurzinger N, Ugurel S, Brocker EB, Becker JC. Therapy of metastasized Merkel cell carcinoma with liposomal doxorubicin in combination with radiotherapy. J Dtsch Dermatol Ges (2009) 7:521-5. doi:10.1111/j.1610-0387. 2008.06990.x

51. Wong KC, Zuletta F, Clarke SJ, Kenndy PJ. Clinical management and treatment outcomes of Merkel cell carcinoma. Aust N Z J Surg (1998) 68:354-8.

Conflict of Interest Statement: The authors declare that the research was conducted in the absence of any commercial or financial relationships that could be construed as a potential conflict of interest.

Received: 15 September 2013; accepted: 25 October 2013; published online: 14 November 2013.

Citation: Hasan S, Liu L, Triplet J, Li Z and Mansur D (2013) The role of postoperative radiation and chemoradiation in Merkel cell carcinoma: a systematic review of the literature. Front. Oncol. 3:276. doi: 10.3389/fonc.2013.00276

This article was submitted to Radiation Oncology, a section of the journal Frontiers in Oncology.

Copyright (C) 2013 Hasan, Liu, Triplet, Li and Mansur. This is an open-access article distributed under the terms of the Creative Commons Attribution License (CC BY). The use, distribution or reproduction in other forums is permitted, provided the original author(s) or licensor are credited and that the original publication in this journal is cited, in accordance with accepted academic practice. No use, distribution or reproduction is permitted which does not comply with these terms. 